\title{
Tarla Küsküt'ünün (Cuscuta campestris Yunck.) Dila biberi (Capsicum annum L.)'nin fenolojik ve pomolojik özelliklerine etkisi
}

\section{The effect of field dodder (Cuscuta campestris Yunck.) on the phenological and pomological characteristics of Dila pepper (Capsicum annum L.)}

\author{
Tamer ÜSTÜNER ${ }^{1 *}$ iD \\ ${ }^{1}$ Sütçü İmam Üniversitesi, Ziraat Fakültesi, Bitki Koruma Bölümü, Kahramanmaraş
}

To cite this article:

Üstüner, T. (2020). Tarla küsküt'ün (Cuscuta campestris Yunck.) Dila biberi (Capsicum annum L.) fenolojik ve pomolojik özelliklerine etkisi. Harran Tarım ve Gıda Bilimleri Dergisi, 24(1): 53-63.

DOI:10.29050/harranziraat.621271

Address for Correspondence: Tamer ÜSTÜNER

e-mail:

tamerustuner@ksu.edu.tr

Received Date:

17.09.2019

Accepted Date:

01.11 .2019
Öz

Bu araştırmada Tarla küsküt'ün (Cuscuta campestris Yunck.) Dila biberi (Capsicum annum L.) fenolojik ve pomolojik özelliklerine etkisi araştııılmıştır. Aynı zamanda, deneme alanında Tarla küsküt yoğunluğu fide evresinde 19.58 adet $\mathrm{m}^{-2}$, çiçeklenme evresinde 10.90 adet sürgün/bitki ve meyve evresinde ise 14.75 adet sürgün/bitki bulunmuştur. Tarla küsküt'ün yoğunluk skalasına göre her üç evrede de çok yoğun olduğu hesaplanmıştır. Küskütün Dila biberine farklı 3 dönemde (Fide, Çiçeklenme ve Meyve oluşum evresinde) infekte edilerek biberin fenolojik ve pomolojik özelliklerine etkisi araştırılmıştır. Tarla küsküt'ün biberde meydana getirdiği fenolojik ve pomolojik kayıpların toplamı fide evresinde \% 100 , çiçek evresinde $\% 52.97$ ve meyve evresinde ise \% 27.73 hesaplanmıştır. Tarla küskütün biber veriminde meydana getirdiği kayıp oranı ise; fide evresinde infeksiyon olduğunda \% 100, çiçek evresinde \% 34.22 ve meyve evresinde \%17.02 hesaplanmıştır. Tarla küsküt'ün Dila biberi fenolojik ve pomolojik özelliklerine etkisi istatistiki analiz sonucuna göre önemli ve farklı bulunmuştur. Dila biberinin Tarla Küskütün'e karşı hassas olduğu bu çalışma ile ortaya konmuştur.

Anahtar Kelimeler: Dila biberi (Capsicum annum L.), Tarla küsküt'ü (Cuscuta campestris Yunck.), Yoğunluk, Fenoloji ve pomoloji

\section{ABSTRACT}

In this study, the effect of field dodder (Cuscuta campestris Yunck.) on the phenological and pomological characteristics of Dila pepper (Capsicum annum L.) was investigated. At the same time, dodder density in the trial area was $19.58 / \mathrm{m}^{2}$ in the seedling stage, 10.90 branch/plant in flowering stage and 14.75 branch/plant in fruit stage. It was calculated that the field dodder was very dense in all three stages according to the density scale. The effects of dodder on the phenological and pomological properties of the pepper were investigated in 3 different periods (seedling, flowering and fruit formation stage). The sum of phenological and pomological losses caused by field dodder in pepper was calculated as $100 \%$ in seedling stage, $52.97 \%$ in flower stage and $27.73 \%$ in fruit stage. The rate of loss caused by field dodder in pepper yield is $100 \%$ loss in seedling stage, $34.22 \%$ in flower stage and $\mathbf{1 7 . 0 2} \%$ in fruit stage. The effect of field dodder on the phenological and pomological characteristics of Dila pepper was found to be significant and different according to the results of statistical analysis. Dila pepper has been shown to be sensitive to field dodder in this study.

(C) Copyright 2018 by Harran University Faculty of Agriculture. Available on-line at www.dergipark.gov.tr/harranziraat

Key Words: Dila pepper (Capsicum annum L.), Field dodder (Cuscuta campestris Yunck.), Density, Phenology and pomology 
Giriş

Biber (Capsicum annum L.), Dünyada ve Ülkemizde çok geniş yelpazede tüketilen önemli bir sebze türüdür. Dünya biber üretiminde ilk üç sırada bulunan ülkeler; Vietnam 252.576 ton ile 1.sırada, Endonezya 87.029 ton ile 2.sırada ve Brezilya 79.371 ton ile 3.sırada yer almıştır (FAO 2017). Türkiye' de biber üretimi illere göre ise Adana 106.372 ton ile 1.sırada, Antalya 94.192 ton ile 2.sırada ve Bursa 83.793 ton ile 3.cü sırada yer alırken Kahramanmaraş ise 12.146 ton ile 9.cu sırada yer almıştır (TUiK, 2018).

Ülkemizde kırmızıbiber ekim alanının yaklaşık $\% 48$ 'i ve üretimin ise $\% 65^{\prime} i$ Kahramanmaraş ve Gaziantep illerinde yapılmaktadır (Akbay ve ark., 2012). Kahramanmaraş'ta üretilen biberin büyük bir kısmı baharat olarak kullanılmak üzere toz biber ve pul biber yapımında kullanılmaktadır. Özellikle ülkemizin birçok bölgesinde talebinin yoğun olduğu toz biber, pul biber ve salça yapımına da bu kalite yansımakta ve bu özellikler Kahramanmaraş biberinin önemini daha fazla arttırmaktadır (Duman ve ark., 2002).

Ekonomik değeri oldukça yüksek olan kırmızıbiber, $A$ ve $C$ vitaminlerince oldukça zengindir (Doymaz ve Pala, 2002). Taze tüketimin yanında, toz biber, salça, közleme, sos, turşu ve ana yemeklerin içerisinde çok değişik şekillerde değerlendirilmekte ve konserve içeriğinde aromatik besin maddesi olarak kullanılmaktadır (Topak ve ark., 2008).

Biber yetiştiriciliğinde hastalık ve zararlılar gibi birçok sorunla karşılaşılmaktadır. Bu sorunlardan bir tanesi de yabancı otlardır. Yabancı otlar biber ile su ve suda erimiş besin elementleri ( $N, P, K, C a$, $\mathrm{Mg}, \mathrm{Fe}, \mathrm{Zn}$ vb.) yönünden rekabete girerek biber bitkisinin hem vejetatif hem de generatif gelişimini olumsuz etkilemektedir. Biber'de sorun olan önemli yabancl ot türlerinden biri de küsküt'tür (Cuscuta spp.). Bu tam parazit bitki olup tüm besin elementlerini konukçusu olan kültür bitkilerinden almaktadır. Dolayısıyla kültür bitkilerinde hem verim hem de kalite kaybına neden olmaktadır. Parazit bitkiler, yaşamlarının bir bölümünde ya da tamamında bir konukçu bitkiye ihtiyaç gösteren bitkilerdir. Bitki gövdesi genellikle ipliksi yapıdadır. Tarla Küsküt'ü (Cuscuta campestris Yunc.), Cuscuta cinsi, Convolvulaceae familyası, Solanales takımına ait yıllık ve tam parazit bir bitkidir. Tarla küsküt'ü tutunduğu bitkinin etrafını sararak, güneşlenme, havalanma, gelişme ve büyüme gibi fizyolojik faaliyetlerine de engel olduğundan dolayı kültür bitkisini zayıf ve güçsüz bırakarak verim ve kalitenin önemli ölçüde düşmesine sebep olan tam parazit bitkidir. Küskütün yaprakları yok ve klorofil içermez. Küsküt sahip olduğu haustorium ile konakçı bitkilerden beslenmektedir (Yuncker, 1932; Davis, 1978; Dawson, 1984; Fang ve ark., 1995).

Küsküt turuncu gövde üzerinde çiçekleri küçük olup kimos çiçek durumunda olup salkım halinde çiçekler açmaktadır. Çiçekler 2-3 mm boyunda, pedisel (çiçek sapı), çiçek boyundan kısa, çiçekler kompakt çiçek topluluklarında toplanmıştır. Kapsül 3.0-3.5 mm çapında basık yuvarlak şekillidir. Meyve kapsülü içerisinde sarımsıturuncu renkte daha sert kabuklu tohumlar bulunur (Lawrence, 1965). Küsküt'ün yaşam döngüsü, tohum çimlenme evresi, konukçuya tutunmadan önceki evre ve parazitik evre konukçu üzerindeki gelişimi olmak üzere 3 evrede görülür. Küsküt gövdesi konukçu bulup tutunursa yaşamını sürdürür, tutunamazsa ölür. Küskütün gövde ucu saat ibresinin aksi yönünde hareket ederek ulaştığı konukçuya sarılır. Böylece konukçusundan yaşamı için gerekli su, organik ve inorganik maddeleri alır (Nemli, 1978; Agrios, 2005; Lanini ve Kogan, 2005).

C. campestris Kuzey Amerika orijinli olup, Güney Amerika, Avrupa, Asya, Afrika ve Avusturalya kıtalarında yaygındır. Tarla küsküt'ü dünyada geniş bir coğrafi dağılıma sahip olup, birçok tarla bitkilerinin yanı sıra; biber, domates, patlıcan, havuç, yonca, soğan, baklagil, kavun, karpuz, patates, karabiber ve şeker pancarını parazitleyerek beslenmekte ve \% 50'ye yakın verim kaybı bazı durumlarda ise \% 90'a varan verim kaybı olabilmektedir (Parker ve Riches, 1993; Holm ve ark., 1997; Nadler-Hassar ve Rubin, 2003; Lanini ve Kogan, 2005; Zharasov, 2009). Dünya genelinde küsküt'ün 200 tür ve 70 varyetesi bulunmaktadır (Costea ve Stevanovic, 2010). 
Davis (1978) tarafından Türkiye'de yapılan bir araştırmada, 21 adet Cuscuta taksonu bulunduğu, Kahramanmaraş'ta ise 2 tür doğal olarak yayılış gösterdiği bildirilmiştir. Anadolu'da $C$. campestris'in 55 konukçusu saptanmıştır. Çoğunlukla otsu olan bitkilerden 27'sinin tarım bitkisi olduğu anlaşılmıştır. Bu türün en yaygın olarak bulunduğu kültür bitkileri; Beta vulgaris L., Medicago sativa L., Trifolium spp., Vicia faba L., C. annuum L., Allium cepa L., Daucus carota L., Vicia sativa L., Solanum melongena L., Cicer arietinum L., Vitis vinifera L., Cucumis melo L., Solonum tuberosum L. ve Lycopersicon esculentum Mill. gibi bitkilerinin olduğu bildirilmiştir (Nemli, 1978; Parker ve Riches, 1993).

Anadolu'da kültür bitkilerinde $C$. campestris, $C$. europaea ve C. epithymum \% 25-49 oranında rastlanmıştır. Tokat ilinde şeker pancarı üretiminde $C$. campestris oranı \% 32-36 oranında gözlenmiştir (Kadıŏlu ve ark., 2015). Kayseri ilinde ise şeker pancarında verim oranını \% 46 azaltmıştır (Akça ve Işık, 2016). Üstüner ve Öztürk (2018) tarafından Tarla küsküt'ün şeker pancarı verim ve kalite değerlerinin kontrole göre önemli derecede azaldığı bildirilmiştir. Çakır ve Üstüner (2019) tarafından Tarla küsküt'ün mercimek agronomik özelliklerine önemli oranda etki yaptığı tespit edilmiştir.

Dünyada ve Türkiye'de bugüne kadar Tarla küskütün Dila biberin fenolojik ve pomolojik özelliklerine etkisi ile ilgili hiçbir araştırmaya rastlanılmamıştır. Bu nedenle araştırmanın amacı Kahramanmaraş koşullarında Tarla küsküt'ün Dila biberi fenolojik ve pomolojik özelliklerine etkisinin araştırılmasıdır.

\section{Materyal ve Yöntem}

\section{Materyaller}

$\mathrm{Bu}$ araştırmanın materyalleri; Dila biberi, Tarla küsküt'ü (Cuscuta campestris Yunck.) ve Küsküt tohumunda dormansiyi kırmak için Indol Butirik asit kullanılmıştır.

Dila biberi Doğu Akdeniz Geçit Kuşağı Tarımsal Araştırma Enstitüsü tarafından 2017 yılında tescillenmiştir. Dila biberi pul biberi çeşidi olup, geniş yapraklı, kuvvetli bitki yapısına sahiptir. Orta erkenci olup, yaş kırmız biber verimi, $2500 \mathrm{~kg} / \mathrm{da}$, meyve ağırlığı $11.74 \mathrm{~g} /$ adet, meyve eni $32.20 \mathrm{~mm}$ ve meyve boyu $88.26 \mathrm{~mm}$ (Anonim, 2017).

Dila biber tohumu oval şekilli ve rengi açık sarıdır. Tarla küsküt tohumu ise sarıdan-koyu kahverengine kadar değişir (Şekil 1). Hem sera hem tarla koşullarında yapılan çalışmada küsküt tohumlarında dormansiyi kırmak amacıyla $30 \mathrm{dk}$ süreyle Indol Butirik asit solüsyonun da tutulmuştur. Bu çalışmanın amacı Kahramanmaraş Sütçü İmam Üniversitesi, Ziraat Fakültesi seralarında viyollere ekilen biber ve küsküt tohumların hem çimlenme zamanlarını hemde küskütün biber fenolojik ve pomoliojik özelliklerine etkilerini araştırmaktır.

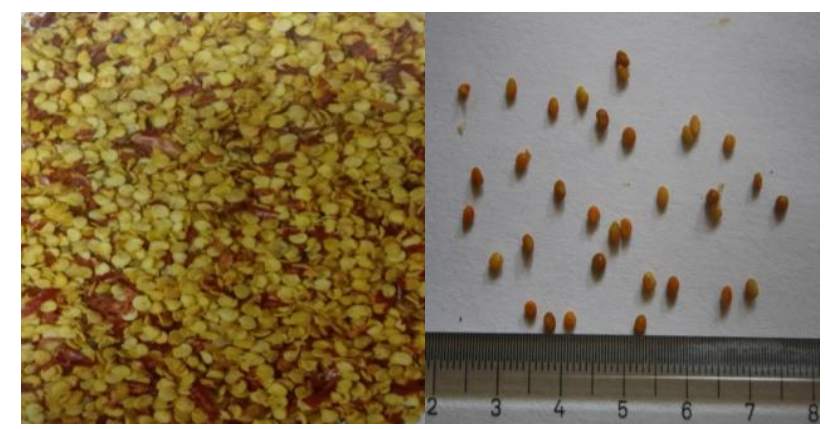

Şekil 1. Dila biberi ve tarla küsküt tohumunun genel görünümü (orijinal)

Figure 1. General view of Dila pepper and field dodder seed (original)

Küsküt, Cuscuta cinsi ve Cuscutaceae familyasında yer alan tam parazit bir bitkidir (Yuncker, 1932). Ancak bitki bazı araştırmacılara tarafından Convolvulceae familyasına dahil edilmektedir. Bitki turuncu-sarımsı renkli, ipliksi ve yapraksız gövdelidir (Şekil 2). Küsküt gövdesi ikiye dallanarak gelişme göstermektedir.

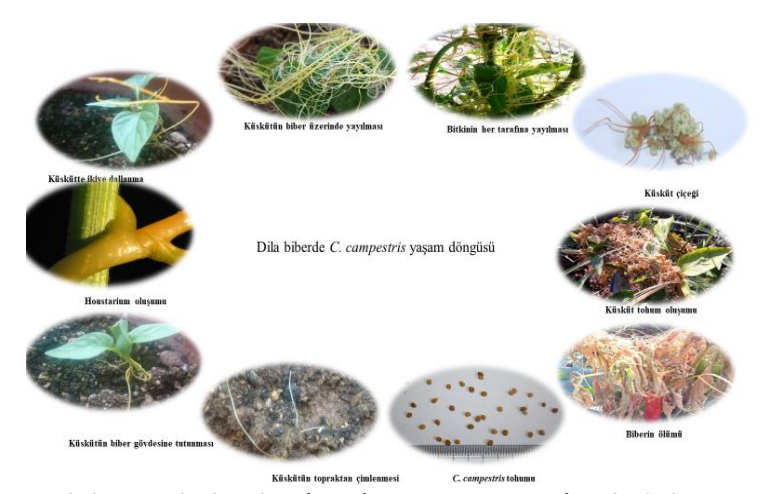

Şekil 2.Tarla küsküt'ün (C. campestris ) Dila biberi üzerinde yaşam döngüsü (orijinal)

Figure 2.The life cycle of field dodder (C. campestris) on Dila pepper (original) 
Dila biberi fide ve çiçeği şekil 3'de gösterilmiştir.

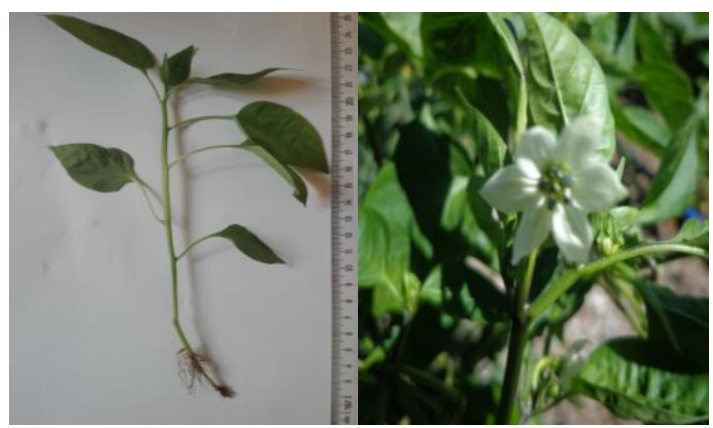

Şekil 3. Dila Biber fidesi ve çiçeğin genel görünümü (orijinal) Figure 3. General view of Dila pepper seedlings and flower (original)

\section{Yöntem}

Bu çalışma Kahramanmaraş Sütçü İmam Üniversitesi, Ziraat Fakültesi sera ve Bitki Koruma Bölümü uygulama arazisinde yapılmıştır. Araştırmada Dila biberi deneme deseni; Tesadüfi deneme desenine göre planlanmıştır. Deneme deseni 3 blok ve her blokta fide dönemi, çiçeklenme ve meyve dönemi olmak üzere küsküt'lü ve kontrol (küsküt'süz) parselleri olmak üzere 6 farklı karakterden oluşmuştur. Parsel boyu $10 \mathrm{~m}$ eni ise $2.80 \mathrm{~cm}$ olarak planlanmıştır. Her parsel arası $100 \mathrm{~cm}$ bloklar arası ise $2 \mathrm{~m}$ kenar tesir payı bırakılmıştır. Her parselde 4 sıra ve sıra arası mesafe $70 \mathrm{~cm}$ sıra üzeri ise $20 \mathrm{~cm}$ olacak şekilde planlanmıştır.

Dila biber deneme parsellerinde yabancl ot sayımı Odum (1983)'a göre, yabancı ot yoğunluğu ise Güncan'a (2001) göre hesaplanmıştır.

Yoğunluk= $B / n$

$-B=$ Alınan örnekte toplam birey sayısı, $-n=$ Alınan örnek sayısı

Yabancı ot yoğunluk skalası Üstüner ve Güncan (2002), küsküt infeksiyon oranı ise Tepe ve ark. (1997)'na göre belirlenmiştir.

\section{Deneme alanın iklim özellikleri}

Kahramanmaraş ili, Türkiye'nin Doğu Akdeniz Bölgesinde $38^{\circ} .02^{\prime}$ ve $38^{\circ} .24^{\prime}$ kuzey enlemi, $36^{\circ} .48^{\prime}$ ve $36^{\circ} .91$ doğu boylamında yer alan ve 558 m’lik rakıma sahiptir. Bu ilin merkezi Akdeniz iklimine sahiptir. Araştırmanın yürütüldüğü 2018 yılında bitki gelişme döneminde belirlenen NisanAralık dönemine ait iklim verileri çizelge 1'de verilmiştir.

Çizelge 1. Kahramanmaraş ili 2018 yılı iklim verileri (Anonim, 2018)

Table 1. Kahramanmaras province 2018 climate data (Anonymous, 2018)

\begin{tabular}{|c|c|c|c|c|c|c|c|c|c|}
\hline $\begin{array}{l}\text { PARAMETRELER } \\
\text { PARAMETERS }\end{array}$ & $\begin{array}{l}\text { Nisan } \\
\text { April }\end{array}$ & $\begin{array}{l}\text { Mayıs } \\
\text { May }\end{array}$ & $\begin{array}{l}\text { Haziran } \\
\text { June }\end{array}$ & $\begin{array}{l}\text { Temmuz } \\
\text { July }\end{array}$ & $\begin{array}{l}\text { Ağustos } \\
\text { August }\end{array}$ & $\begin{array}{l}\text { Eylül } \\
\text { September }\end{array}$ & $\begin{array}{l}\text { Ekim } \\
\text { October }\end{array}$ & $\begin{array}{l}\text { Kasım } \\
\text { November }\end{array}$ & $\begin{array}{l}\text { Aralık } \\
\text { December }\end{array}$ \\
\hline $\begin{array}{l}\text { Ortalama } \\
\text { minumum } \\
\text { sıcaklık }\left({ }^{0} \mathrm{C}\right) / \\
\text { Average } \\
\text { minimum } \\
\text { temperature }\end{array}$ & 9.8 & 13.9 & 18.6 & 21.9 & 22.0 & 18.2 & 12.8 & 7.0 & 3.2 \\
\hline $\begin{array}{l}\text { Ortalama } \\
\text { maksimum } \\
\text { sıcaklık }\left({ }^{0} \mathrm{C}\right) / \\
\text { Average } \\
\text { maximum } \\
\text { temperature }\end{array}$ & 21.2 & 26.7 & 31.5 & 35.5 & 35.9 & 32.5 & 26.0 & 17.8 & 11.1 \\
\hline $\begin{array}{l}\text { Ortalama } \\
\text { sıcaklık }\left({ }^{0} \mathrm{C}\right) / \\
\text { Average } \\
\text { temperature }\end{array}$ & 15.5 & 20.3 & 25.2 & 28.4 & 28.5 & 25.3 & 19.1 & 11.7 & 6.8 \\
\hline $\begin{array}{l}\text { Ortalama Nem } \\
\text { (\%)/Average } \\
\text { Humidity }\end{array}$ & 45.6 & 54.9 & 47.2 & 48.0 & 46.5 & 45.1 & 53.1 & 43.3 & 62.2 \\
\hline $\begin{array}{l}\text { Aylık toplam } \\
\text { yağış (mm)/ } \\
\text { Total monthly } \\
\text { precipitation }\end{array}$ & 72.8 & 41.9 & 7.4 & 1.1 & 0.9 & 8.9 & 47.9 & 81.7 & 127.0 \\
\hline $\begin{array}{l}\text { Yağışlı gün } \\
\text { sayısı (Gün)/ } \\
\text { Number of } \\
\text { rainy days } \\
\text { (Days) }\end{array}$ & 11 & 7 & 4 & 3 & 2 & 5 & 8 & 13 & 17 \\
\hline
\end{tabular}




\section{Deneme alanın toprak özellikleri}

Deneme alanı toprak analizleri KSÜ, Ziraat Fakültesi, Toprak Bilimi ve Bitki Besleme bölüm laboratuvarında yapılmıştır. Toprak özellikleri çizelge 2'de verilmiştir.

Çizelge 2. Deneme alanın toprak analiz değerleri Table 2. Soil analysis values of the trial area

\begin{tabular}{lcc}
\hline $\begin{array}{l}\text { Toprak içeriği/ Soil } \\
\text { content }\end{array}$ & Birimi/ Unit of & Oran/ Rate \\
\hline $\mathrm{pH} / \mathrm{pH}$ & $\%$ & 6.84 \\
\hline Toplam Tuz/ Total Salt & $\%$ & 0.17 \\
\hline Kireç/ Lime & $\%$ & 7.69 \\
\hline $\begin{array}{l}\text { Organik Madde/ } \\
\text { Organic Matter }\end{array}$ & (mg kg-1) & 3.21 \\
\hline Alınabilir P/ Available P & (mg kg-1) & 200 \\
\hline Alınabilir K/ Available K & (mg kg-1) & 11100 \\
\hline $\begin{array}{l}\text { Alınabilir Ca/ Available } \\
\text { Ca }\end{array}$ & (mg kg-1) & 620 \\
\hline $\begin{array}{l}\text { Alınabilir Mg/ Available } \\
\text { Mg }\end{array}$ & (mg kg-1) & 35.5 \\
\hline $\begin{array}{l}\text { Alınabilir Na/ Available } \\
\text { Na }\end{array}$ & (mg kg-1) & 5.8 \\
\hline $\begin{array}{l}\text { Alınabilir Fe/ Available } \\
\text { Fe }\end{array}$ & (mg kg-1) & 0.2 \\
\hline $\begin{array}{l}\text { Alınabilir Zn/ Available } \\
\text { Zn }\end{array}$ & (mg kg-1) & 0.9 \\
\hline $\begin{array}{l}\text { Alınabilir Cu/ Available } \\
\text { Cu }\end{array}$ & (mg kg-1) & 7.05 \\
\hline $\begin{array}{l}\text { Alınabilir Mn/ Available } \\
\text { Mn }\end{array}$ & $\begin{array}{l}\text { Küng kg-1) } \\
\text { Ni }\end{array}$ & 51.47 \\
\hline $\begin{array}{l}\text { Künab/Sand } \\
\text { Kil/ Clay }\end{array}$ & 26.36 \\
\hline
\end{tabular}

\section{Sera koşullarında tohum ekimi}

Serada $23{ }^{\circ} \mathrm{C}^{\prime}$ de sicaklık ve \%54 nemli ortamda 20.03.2018 tarihinde viyollere biber ve küsküt tohumları ekilmiştir. Biber fideleri $10 \mathrm{~cm}$ boyunda iken deneme alanına küsküt ile infekteli ve infektesiz olarak dikimi yapılmıştır.

\section{Tarla koşullarında fide dikimi}

Biber fideleri küsküt ile infekteli olanlar ayrı infektesiz olanlar ayrı parsellere 20.04.2018 tarihinde dikilmiştir. Daha sonra damla sulama sistemi döşenmiştir. Tarlada biber deneme alanına dekara $25 \mathrm{~kg}$ azot, $8 \mathrm{~kg}$ fosfor, $25 \mathrm{~kg}$ potasyum ve $12 \mathrm{~kg}$ hesabıyla kalsiyumlu ticari gübre verilmiştir. Azotun \% 50'si dikim öncesi toprak işlemede, \% 25'i ara çapada, geri kalan \% $25^{\prime} \mathrm{i}$ de çiçeklenmeden önce, fosforun tamamı dikim öncesi toprak işlemede, potasyumun \% 6065 'i dikim öncesi toprak işlemede, geri kalan \% 35-40'ı ise çiçeklenme öncesinde deneme alanına uygulanmıştır.

\section{Dila Biberi meyve özelliği}

Dila biberinin meyveleri ince meyve etine sahip sanayiye uygun bir çeşittir. Meyve ağırlığı 11.74 g/adet, eni $32.20 \mathrm{~mm}$, boyu $88.26 \mathrm{~mm}$, meyve eti kalınlığı ise 1.05 mm'dir (Anonim, 2017). Daha sonra çiçek ve meyve periyodu karışık olarak devam etmiştir.

\section{Istatistiksel analiz}

Elde edilen verilerin istatistiksel değerlendirilmesi SPSS paket programı (SPSS) ile yapılmıştır. Bu verilerde $(n=10)$, sonuçlar üzerine parametrelerin Independent $T$ testi ile analizi yapılmış ve ortalamalar arasındaki farklılıklar hesaplanmıştır.

\section{Araştırma Bulguları ve Tartışma}

\section{Sera koşullarında}

Serada $23{ }^{\circ} \mathrm{C}^{\prime}$ de sıcaklık ve \%54 nemli ortamda 20.03.2018 tarihinde viyollere ekilen biber tohumları 8. günde çimlenmeye başlamıştır. Tarla küsküt'ün de ise 25. günde çimlenme gözlenmiştir. Küsküt biber fidesi gövdesine sarılarak houstarium oluşturmakta ve daha sonra toprakla ilişkisini kesmektedir. Küsküt gövdeleri ikiye dallanarak hızla biber fidelerini sarmıştır (Şekil 4).

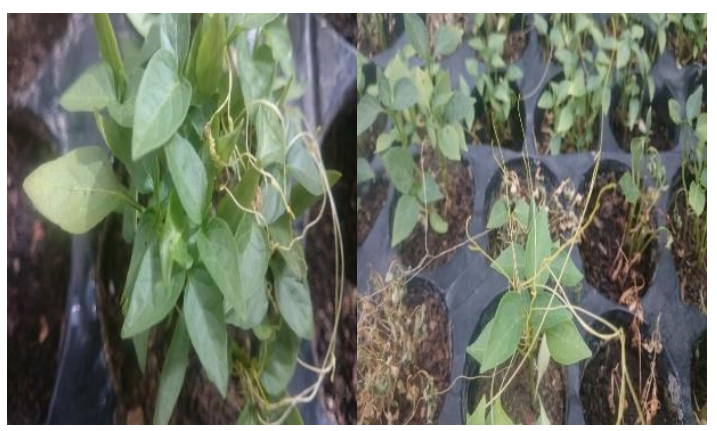

Şekil 4. Tarla küsküt'ün viyolde biber fidelerine infeksiyonu (orijinal)

Figure 4. Field dodder infection to pepper seedlings in viol (original) 


\section{Tarla koşullarında}

Küsküt'ün Dila biberine farklı 3 dönemde (Fide, Çiçeklenme ve Meyve oluşum evresinde) infekte edilerek biberin fenolojik ve pomolojik özelliklerine etkisi araştırılmıştır.

$\mathrm{Bu}$ araştırmada biber fide evresinde Tarla küsküt yoğunluğu 19.58 adet $/ \mathrm{m}^{2}$, çiçeklenme evresinde küsküt yoğunluğu 10.90 adet sürgün/bitki, meyve evresinde ise 14.75 adet sürgün/bitki çok yoğun olduğu hesaplanmıştır (Şekil 5). Biber fide evresinde infeksiyon sonucunda ölüm görüldüğü için hastalık şiddeti çok yüksek olup etki oranı \% 100 bulunmuştur.

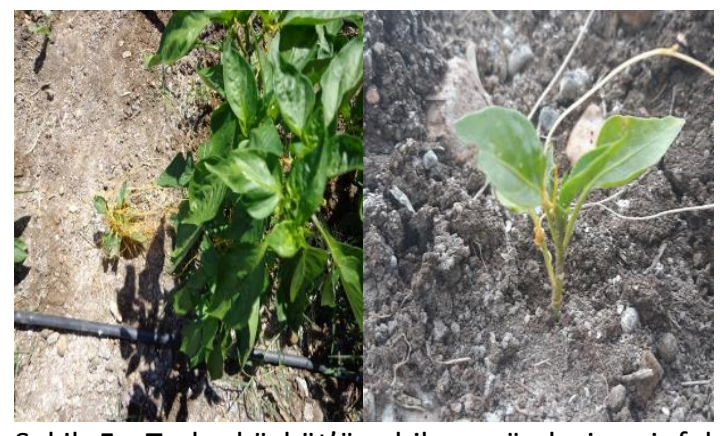

Şekil 5. Tarla küsküt'ün biber gövdesine infeksiyonu ve küskütsüz biber ile boy farkı $(28-30 \mathrm{~cm})$ (orijinal)

Figure 5. Infection of field dodder to pepper body and height difference with non-dodder pepper $(28-30 \mathrm{~cm})$ (original)

Tarla küsküt gelişmesi biber gelişmesinden çok daha hızlı olmuştur. Özellikle küsküt gövdeleri ikiye dallanarak biber fidesini 8-10 gün içerisinde tamamen sarmıştır (Şekil 6). Biber dal ve gövdesinde oluşturduğu houstariumlar vasıtasıyla konukçusunun besin elementlerini küsküt kullanmıştır.

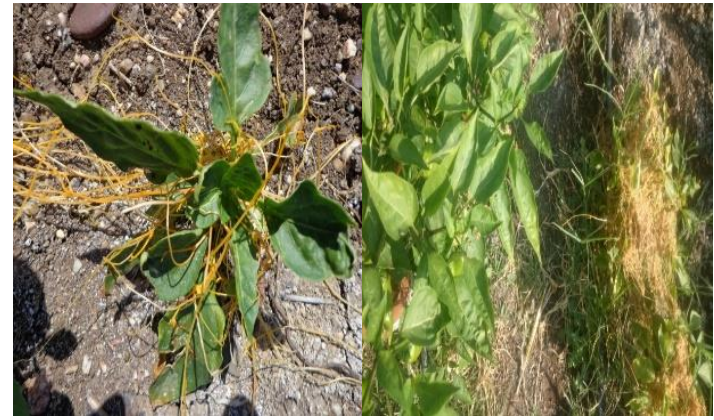

Şekil 6. Tarla küsküt ile infekteli $(13 \mathrm{~cm})$ ve infektesiz biber $(32 \mathrm{~cm})$ (orijinal)

Figure 6. Field dodder with infested $(13 \mathrm{~cm})$ and uninfected pepper $(32 \mathrm{~cm})$ (original)

Tarla küsküt'ü biberin üzerini tamamen sararak güneş ışığından faydalanmasını ve buna bağı olarak bitki fotosentezini önlediği gözlenmiştir. Tarla küsküt'ü biber fide evresinde inefkte ettiğinde biber fideleri infeksiyondan 35-39 gün sonra tamamen kurumuştur (Şekil 7).

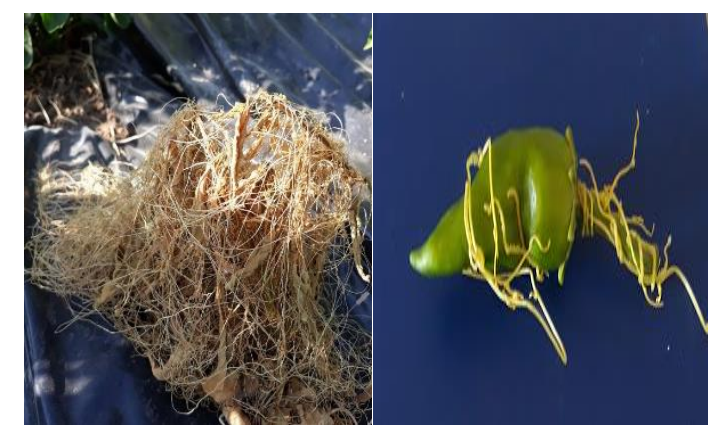

Şekil 7. Biber fide evresinde tarla küsküt ile infekte edildiğinde fide ölümü ve meyve şekil bozukluğu (orijinal)

Figure7. Seedling death when pepper is infected with dodder during seedling stage and fruit deformation (original)

Çizelge 3.Tarla küsküt'ün Dila biberi fide evresinde fenolojik özelliklerine etkisi

Table 3. The effect of field dodder on phenological properties of Dila pepper seedling stage

\begin{tabular}{|c|c|c|c|}
\hline \multirow{2}{*}{$\begin{array}{c}\text { Biber Fenolojisi } \\
\text { Pepper Phenology }\end{array}$} & \multicolumn{3}{|c|}{$\begin{array}{c}\text { Fide evresi } \\
\text { Seedling stage }\end{array}$} \\
\hline & $\begin{array}{c}\text { Küsküt'lü } \\
\text { With dodder }\end{array}$ & $\begin{array}{l}\text { Küsküt'süz } \\
\text { Undodder }\end{array}$ & $\begin{array}{l}\text { t ve } P \text { değerleri } \\
t \text { and } P \text { values }\end{array}$ \\
\hline Bitki Boyu (cm)/ Plant Height (cm) & $10.66 \pm 0.537$ & $22.62 \pm 0.713$ & $t=13.40, d f: 18, P<0.001$ \\
\hline Çiçek sayısı (adet)/ Number of flowers (pcs) & $0 \pm 0$ & $12.4 \pm 0.654$ & $t=18.40, d f: 18, P<0.001$ \\
\hline Meyve sayısı(adet)/ Number of fruits (pcs) & $0 \pm 0$ & $2.5 \pm 0.401$ & $t=6.228, d f: 18, P<0.001$ \\
\hline Dal sayısı (adet)/ Number of branches (pcs) & $2 \pm 0.258$ & $6.2 \pm 0.553$ & $t=6.874, d f: 18, P<0.001$ \\
\hline
\end{tabular}


Biber fide evresinde Küsküt infekte edildiğinde; bitki boyu ortalaması $10.66 \mathrm{~cm}$, dal sayısı 2 adet, çiçek ve meyve sayısı 0 adet hesaplanmıştır (Çizelge 3). Küsküt'ün biber fide evresinde fenoloik özelliklerine etkisi t ve $P$ değeri yönünden çok önemli bulunmuştur.

$\mathrm{Bu}$ infekteli fideler $12-13 \mathrm{~cm}$ boyunda iken kuruyarak bitki ölümü gözlenmiştir. Kontrol (Küsküt'süz) parselde ise bitki boyu ortalaması $22.62 \mathrm{~cm}$, dal sayısı 6.20 adet, çiçek sayısı 12.40 adet ve meyve sayısı 2.50 adet hesaplanmıştır. İnfekteli biberlerin tamamı çiçeklenme öncesi tamamen kuruduğu için bu evrede küskütün zararı \% 100 bulunmuştur. Biber çiçeklenme evresinde Küsküt infekte edildiğinde bitki boyu $20.11 \mathrm{~cm}$, dal sayısı 10.90, çiçek sayısı 9.0 ve meyve sayısı 4.5 adet, Kontrol parsellerinde ise $27.82 \mathrm{~cm}, 16.60$ adet, 16.50 ve 5.90 adet olduğu hesaplanmıştır (Çizelge 4).

Çizelge 4. Tarla küsküt'ün Dila biberi çiçeklenme evresinde fenolojik özelliklere etkisi

Table 4.The effect of field dodder on phenological characteristics during the flowering stage of Dila pepper

\begin{tabular}{lccc}
\hline \multicolumn{1}{c}{$\begin{array}{c}\text { Biber Fenolojisi } \\
\text { Pepper Phenology }\end{array}$} & \multicolumn{2}{c}{$\begin{array}{c}\text { Çiçek evresi } \\
\text { Flower stage }\end{array}$} \\
\cline { 2 - 4 } & $\begin{array}{c}\text { Küsküt'lü } \\
\text { With dodder }\end{array}$ & $\begin{array}{c}\text { Küsküt'süz } \\
\text { Undodder }\end{array}$ & $\begin{array}{c}\mathrm{t} \text { ve } \mathrm{P} \text { değerleri } \\
\text { t and } P \text { values }\end{array}$ \\
\hline Bitki Boyu (cm)/ Plant Height (cm) & $20.11 \pm 0.33$ & $27.82 \pm 0.784$ & $\mathrm{t}=9.066, \mathrm{df}: 18, \mathrm{P}<0.001$ \\
\hline Çiçek sayısı (adet)/ Number of flowers (pcs) & $9 \pm 0.26$ & $16.5 \pm 0.43$ & $\mathrm{t}=15.00, \mathrm{df}: 18, \mathrm{P}<0.001$ \\
\hline Meyve sayısı (adet)/ Number of fruits (pcs) & $4.5 \pm 0.43$ & $5.9 \pm 0.378$ & $\mathrm{t}=2.45, \mathrm{df}: 18, \mathrm{P}=0.025$ \\
\hline Dal sayısı (adet)/ Number of branches (pcs) & $10.9 \pm 0.23$ & $16.6 \pm 0.48$ & $\mathrm{t}=10.751, \mathrm{df}: 18, \mathrm{P}<0.001$ \\
\hline
\end{tabular}

Tarla küsküt'ün Dila biberi çiçeklenme evresinde fenolojik özelliklerine etkisi; biber boyunda \% 7.71'lik azalışa sebep olurken, dal sayısında \% 5.7, çiçeklenme oranında \% 7.5 ve meyve oluşumunda \% $1.4^{\prime}$ lük azalışa sebep olmuştur. Aynı zamanda biberlerde \% 25 oranında kuruma da gözlenmiştir. Küsküt biber çiçek evresinde fenolojik özelliklere \% 47.31 oranında negatif etki yapmıştır. Küsküt'ün biber çiçeklenme evresinde fenoloik özelliklerine etkisi t ve $P$ değeri yönünden önemli bulunmuştur.

Biber meyve evresinde Küsküt infekte edildiğinde bitki boyu $27.70 \mathrm{~cm}$, dal sayısı 16.10, çiçek sayısı 16.30 ve meyve sayısı 11.50 adet hesaplanmıştır. Kontrol parsellerinde ise 43.30 cm, 20.60, 18.80 ve 14.90 adet olduğu hesaplanmıştır (Çizelge 5).

Çizelge 5. Tarla küsküt'ün Dila biberi meyve evresinde fenolojik özelliklere etkisi Table 5. The effect of field dodder on phenological characteristics of Dila pepper fruit stage

\begin{tabular}{lccc}
\hline \multirow{2}{*}{$\begin{array}{c}\text { Biber Fenolojisi } \\
\text { Pepper Phenology }\end{array}$} & \multicolumn{3}{c}{$\begin{array}{c}\text { Meyve evresi } \\
\text { Fruit stage }\end{array}$} \\
\cline { 2 - 4 } & $\begin{array}{c}\text { Küsküt'lü } \\
\text { With dodder }\end{array}$ & $\begin{array}{c}\text { Küsküt'süz } \\
\text { Undodder }\end{array}$ & $\begin{array}{c}\mathrm{t} \text { ve } \mathrm{P} \text { değerleri } \\
\text { t and } P \text { values }\end{array}$ \\
\hline Bitki Boyu (cm)/ Plant Height (cm) & $27.7 \pm 0.472$ & $43.3 \pm 0.87$ & $\mathrm{t}=15.758, \mathrm{df}: 18, \mathrm{P}<0.001$ \\
\hline Çiçek sayısı (adet)/ Number of flowers (pcs) & $16.3 \pm 0.65$ & $18.8 \pm 0.47$ & $\mathrm{t}=3.132, \mathrm{df}: 18, \mathrm{P}<0.05$ \\
\hline Meyve sayısı (adet)/ Number of fruits (pcs) & $11.5 \pm 0.43$ & $14.9 \pm 0.433$ & $\mathrm{t}=5.581, \mathrm{df}: 18, \mathrm{P}<0.001$ \\
\hline Dal sayısı (adet)/ Number of branches (pcs) & $16.1 \pm 0.566$ & $20.6 \pm 0.763$ & $\mathrm{t}=4.735, \mathrm{df}: 18, \mathrm{P}<0.001$ \\
\hline
\end{tabular}

Tarla küsküt'ün Dila biberi meyve evresinde fenolojik özelliklerine etki oranı Biber boyunda \% 15.60 'lık azalışa sebep olurken, dal sayısında \% 4.5, çiçeklenme oranında \% 2.5 ve meyve oluşumunda \% 3.4'lük azalışa sebep olmuştur.
Biber meyve evresinde fenolojik özelliklere \% 26.0 oranında negatif etki yapmıştır.

Tarla küsküt'ün Dila biberi pomolojik özelliklerine etkisi açısından incelendiğinde; Çiçeklenme evresinde Küsküt infekte edildiğinde; 
Biber meyve boyu $5.90 \mathrm{~cm}$, meyve eni $3,10 \mathrm{~cm}$ ve meyve ağırlığı $12.68 \mathrm{~g}$ iken Kontrol parselde ise $8.10 \mathrm{~cm}, 3.50 \mathrm{~cm}$ ve $15.74 \mathrm{~g}$ olduğu hesaplanmıştır (Çizelge 6). Küsküt infekte edildiğinde; Biber meyve boyu \% 2.2, meyve eni
\%0.4 ve meyve ağırlığı \%3.06 azalış gösterdiği hesaplanmıştır. Küsküt'ün biber fenolojik ve pomolojik özelliklerine toplam etkisi \% 52.97 hesaplanmıştır.

Çizelge 6. Tarla küskütün Dila biberi çiçeklenme dönemi pomolojik özelliklerine etkisi

Table 6. The effect of field dodder on pomological properties of Dila pepper in flowering period

\begin{tabular}{lccc}
\hline \multicolumn{1}{c}{$\begin{array}{c}\text { Biber pomolojisi } \\
\text { Pepper pomology }\end{array}$} & \multicolumn{2}{c}{$\begin{array}{c}\text { Çiçek evresi } \\
\text { Flower stage }\end{array}$} \\
\cline { 2 - 4 } & $\begin{array}{c}\text { Küsküt'lü } \\
\text { With dodder }\end{array}$ & $\begin{array}{c}\text { Küsküt'süz } \\
\text { Undodder }\end{array}$ & $\begin{array}{c}\text { t ve P değerleri } \\
\text { t and } P \text { values }\end{array}$ \\
\hline Meyve Boyu $(\mathrm{cm}) /$ Fruit Length $(\mathrm{cm})$ & $5.9 \pm 0.22$ & $8.1 \pm 0.19$ & $\mathrm{t}=7.531, \mathrm{df}: 18, \mathrm{P}<0.001$ \\
\hline Meyve eni $(\mathrm{cm}) /$ Fruit width $(\mathrm{cm})$ & $3.1 \pm 0.146$ & $3.5 \pm 0.162$ & $\mathrm{t}=1.834, \mathrm{df}: 18, \mathrm{P}=0.083$ \\
\hline Meyve ağırlığı $(\mathrm{g}) /$ Fruit weight $(\mathrm{g})$ & $12.68 \pm 0.33$ & $15.74 \pm 0.228$ & $\mathrm{t}=7.624, \mathrm{df}: 18, \mathrm{P}<0.001$ \\
\hline
\end{tabular}

Biber meyvesinin erken evresinde küsküt infeksiyonu gerçekleştiğinde meyve simetriği bozulurken, Küsküt'süz meyvde her hangi bir şekil bozukluğu görülmemiştir.

Meyve evresinde Küsküt infekte edildiğinde Biber meyve boyu $8.20 \mathrm{~cm}$, meyve eni $3,35 \mathrm{~cm}$ ve meyve ağırlığı $15.21 \mathrm{~g}$ iken Kontrol parselde ise meyve boyu $8.28 \mathrm{~cm}$, meyve eni $3,87 \mathrm{~cm}$ ve meyve ağırlığı $16.33 \mathrm{~g}$ olduğu hesaplanmıştır (Çizelge 7). Bu evrede biber meyve boyu \% 0.08 $\mathrm{cm}$, meyve eni $\% 0.52 \mathrm{~cm}$ ve meyve ağırlığı \% $1.12 \mathrm{~g}$ azalış göstermiştir.

Çizelge 7. Tarla küskütün Dila biberi meyve dönemi pomolojik özelliklerine etkisi

Table 7. The effect of field dodder on pomological characteristics of Dila pepper fruit period

\begin{tabular}{lccc}
\hline \multicolumn{1}{c}{$\begin{array}{c}\text { Biber pomolojisi } \\
\text { Pepper pomology }\end{array}$} & \multicolumn{3}{c}{$\begin{array}{c}\text { Meyve evresi } \\
\text { Fruit stage }\end{array}$} \\
\cline { 2 - 4 } & $\begin{array}{c}\text { Küsküt'lü } \\
\text { With dodder }\end{array}$ & $\begin{array}{c}\text { Küsküt'süz } \\
\text { Undodder }\end{array}$ & $\begin{array}{c}\text { t ve } \mathrm{P} \text { değerleri } \\
\text { t and } P \text { values }\end{array}$ \\
\hline Meyve Boyu $(\mathrm{cm}) /$ Fruit Length $(\mathrm{cm})$ & $8.205 \pm 0.075$ & $8.275 \pm 0.124$ & $\mathrm{t}=0.482, \mathrm{df}: 18, \mathrm{P}=0.636$ \\
\hline Meyve eni $(\mathrm{cm}) /$ Fruit width $(\mathrm{cm})$ & $3.35 \pm 0.116$ & $3.87 \pm 0.064$ & $\mathrm{t}=3.87, \mathrm{df}: 18, \mathrm{P}<0.05$ \\
\hline Meyve ağırlığı $(\mathrm{g}) /$ Fruit weight $(\mathrm{g})$ & $15.2 \pm 0.247$ & $16.33 \pm 0.137$ & $\mathrm{t}=3.975, \mathrm{df}: 18, \mathrm{P}<0.001$ \\
\hline
\end{tabular}

Küskütün biber meyve pomolojik özelliklerine etkisi $t$ ve $P$ değeri yönünden önemsiz bulunmuştur. Küsküt'ün biber fenolojik ve pomolojik özelliklerine toplam etkisi \% 27.72 hesaplanmıştır.

Küsküt ile infekteli meyvede erken kızarma görülürken küskütsüz meyvede erken kızarma görülmemiştir. Küsküt biber normal vejetasyonu süresinin 35 gün daha erken olmasına neden olmuştur. Tarla küsküt'ün biberde meydana getirdiği fenolojik ve pomolojik kayıpların toplamı fide evresinde $\% 100$, çiçek evresinde $\% 52.97$ ve meyve evresinde ise \% 27.72 hesaplanmıştır.

Tarla küsküt'ü infekte edilmiş Dila biber parsellerinde ortalama verim; fide evresinde küsküt infeksiyon uygulanan parsellerde verim 0 $\mathrm{kg} / \mathrm{da}$, çiçek evresinde $1573.2 \mathrm{~kg} / \mathrm{da}$ ve meyve evresinde ise $1984.6 \mathrm{~kg} / \mathrm{da}$ iken Kontrol (Küsküt'süz) parselde ise $2391.5 \mathrm{~kg} /$ da verim elde edilmiştir. Tarla küskütün biber veriminde meydana getirdiği kayıp oranı; fide evresinde infeksiyon olduğunda \%100, çiçek evresinde $\% 34.22$ ve meyve evresinde $\% 17.02$ bulunmuştur.

\section{Tartışma}

$\mathrm{Bu}$ araştırmada Tarla küsküt (C. campestris) tohumları sera koşullarında $23{ }^{\circ} \mathrm{C}$ sıcaklık ve \% 54 nemli ortamda optimum seviyede çimlenme göstermiştir. Tarla koşullarında ise $C$. campestris tohumları $15.5^{\circ} \mathrm{C}^{\prime}$ de çimlenmeye başlamıştır. Bu konuda yapılmış diğer çalışmada ise $C$. campestris tohumlarında 5 ve $10{ }^{\circ} \mathrm{C}^{\prime}$ lerde çimlenme 
görülmezken en yüksek çimlenme $C$. campestris için 20-35 ${ }^{\circ} \mathrm{C}$ arasında görülmüştür (Tamer ve Nemli, 2012). Bizim elde ettiğimiz sonuç ile bu literatür arasında benzerlik gözlenmiştir.

Tarla küsküt'ün Dila biberi fenolojik ve pomolojik özelliklerine (Fide, çiçek ve meyve evresi) etkisi farklı oranlarda meydana gelmiştir. Viyollerde biber fide evresinde küsküt inefksiyonu gerçekleştiğinde hastalık şiddeti \% 100 oranında meydana gelmiştir. Bu evrede verim kaybı \% 100 gerçekleşmiştir. Biber çiçeklenme evresinde küsküt infeksiyonu gerçekleştiğinde hastalık şiddeti orta düzeyde gerçekleşmiştir. Biber veriminde azalma görülürken, bu evrede \% 25 oranında ölüm gerçekleşmiştir. Tarla küsküt'ün biber veriminde meydana getirdiği kayıp oranı ise; fide evresinde infeksiyon olduğunda \% 100, çiçek evresinde \% 34.22 ve meyve evresinde \%17.02 hesaplanmıştır.

Dünyada Tarla küsküt'ün verim kaybı ile ilgili yapılan araştırmalarda; Lanini (2004), Tarla küsküt'ün domatesde \% 75, Bewick ve ark., (1988) havuçta \% 70-90, Lanini ve Kogan, (2005) Cuscuta pentagona'nın domateste \% 50-75, yonca alanlarında \% 50, havuç alanlarında ise \% 70-90, Mishra ve ark., (2007) Guizotia abyssinica'da \% 86, Phaseolus radiatus'da \% 82, Sesamum orientale'de \% 67, Cajanus cajan'da \% 25, Mishra (2009) kırmızı biberde \% 60-65, domateste \% 72, nohutta $\% 86$, yoncada $\% 60-70$ ve mercimekte $\%$ 87 oranında verim kaybı tespit etmişlerdir. Sırbistan'da yaklaşık 10 Cuscuta türü tespit edilmiş ve en sık rastlanan tür ise $C$. campestris'dir. Tarla küsküt'ü, Medicago sativa, Beta vulgaris, Allium cepa, Allium sativum, Capsicum annum, Cucumis sativus, Cucurbita pepo, Lycopersicum esculentum ve Nicotiana tabacum gibi kültür bitkilerinde önemli verim kaybı oluşturmuştur (Vrbničanin ve ark., 2013; Krsmanović ve Vrbničanin, 2015). Nijerya'da C. campestris' in Soyafasulyesi, börülce, Biber, domates, yerfıstığı, mısır ve pirinç'e etkileri önemli bulunmuştur (Mustapha ve Gworgwor, 2016). Bu araştırmada elde edilen sonuç ile diğer literatürler, Tarla küsküt'ü tür açısından, biber verim kaybı açısından benzerlik gösterirken sayısal olarak verim kaybının ülkeden ülkeye ve küsküt'ün infeksiyon zamanına göre değişebileceğini göstermiştir.

Türkiye'de Tarla küsküt'ün verim kaybı ile ilgili yapılan araştırmalarda; Davis'in Flora of Turkey (1978) eserinde, Türkiye'de Cuscuta cinsine ait 16 tür tanımlanmış ve en yaygın türlerin; $C$. campestris, C. approximata ve C. monogyna olduğu bildirilmiştir. Anadolu'da kültür alanlarında C. campestris, C. approximata ve C. monogyna özellikle şekerpancarı, biber, soğan, yonca ve yazlık sebzeler üzerinde yoğun görülmüştür (Nemli, 1986). Cuscuta spp.'nin neden olduğu ürün kaybı \% 20-57 arasında değiştiği ancak \%91'e kadar çıkabildiği belirlenmiştir (Nemli ve Öngen, 1982). Türkiye'de C. campestris'in 55 konukçusu belirlenmiş olup bunlardan 27'sinin kültür bitkileri olup bunların; Yonca, pancar, şeker pancarı, biber, tütün, soğan, patates, domates, asma gibi kültür bitkileridir (Nemli, 1986). C. campestris Türkiye'de geniş bir yayılışa sahip olup deniz seviyesinden 1500 m yüksekliğe kadar gelişir. Bu türün konukçuları arasında; Yonca, şeker pancarı, soğan, tütün, anason, kimyon, biber ve nohut (Kaya ve ark., 2018). Üstüner (2018) tarafından yapılan araştırmada, tarla koşullarında $C$. campestris infekte olmuş ve infekte olmamış şeker pancarı çeşidinde, hektar başına elde edilen verim miktarı, sırasıyla $79.573 .9 \mathrm{~kg} /$ ha ve 57.341 .3 $\mathrm{kg} / \mathrm{ha}$ elde edilmiştir. Çakır ve Üstüner (2019) tarafından yapılan araştırmada C. campestris'in mercimek verim ve kalitesini önemli oranda etkilediği bildirilmiştir. Bu çalışma sonucu ile ülkemizde yapılan çalışma sonuçları benzerlik gösterirken zarar oranları rakamsal olarak değişkenlik göstermiştir. Bunun nedeni Tarla küsküt'ün çimlenme dönemi, küsküt'ün kültür bitkisine infeksiyonun farklı fenolojik dönemde olması, iklim ve toprak faktörlerin farklılık göstermesi olabilir.

\section{Sonuç}

Tarla küsküt'ü Kahramanmaraş koşullarında 14 Nisan'dan itibaren hava sıcaklığının $15{ }^{\circ} \mathrm{C}$ üzerine çıktığı zamanda çimlenmeye başlamıştır. Tarla 
küsküt'ün biberin fenolojisine göre en yüksek etkiyi fide evresinde gösterdiği tespit edilmiştir. Viyollerde biber fideleri küsküt ile inefkte edildiğinde biber fideleri çiçeklenme periyoduna giremeden ölüm gerçekleşmiştir. Özellikle biber fideliğinde küsküt infeksiyonu görüldüğünde hastalık şiddeti \% 100 oranında gerçekleşmiştir. Tarla küsküt'ün Dila biberi çiçeklenme ve meyve evresinde fenolojik özelliklerine etki oranı pomolojik özelliklerine etkisinden yüksek bulunmuştur. Tarla küsküt'ün biberde meydana getirdiği fenolojik ve pomolojik kayıpların toplamı fide evresinde en yüksek oranda, 2.sırada çiçek evresinde ve 3.cü sırada meyve evresinde gözlenmiştir. Tarla küsküt'ün biber veriminde meydana getirdiği kayıp oranı ise; fide evresinde infeksiyon olduğunda \% 100 , çiçek evresinde \% 34.22 ve meyve evresinde \% 17.02 hesaplanmıştır. Tarla küsküt'ün biber de oluşturduğu simptomlar; biber fide evresinde kuruma, çiçek evresinde bodurluk, meyvede şekil bozukluğu, güneş ışığını engelleyerek bitkinin zayıf kalması, meyve tutumunda azalma ve biber vejetasyon süresini kısaltmadır. Dila biberin Tarla Küskütüne karşı hassas olduğu bu çalışma ile ortaya konmuştur.

\section{Teşekkür}

Bu projeyi (2018/1-36 LAP ) destekleyen KSÜ, BAP koordinasyon birimine ve Dila biber tohumunu sağlayan Doğu Akdeniz Geçit Kuşağı Tarımsal Araştırma Enstitüsü müdürlüğüne teşekkür ederim.

\section{Kaynaklar}

Agrios, G. N. (2005). Plant pathology, Fifth Edition, Department of Plant Pathology University of Florida, Elsevier Academic Press, 708.

Akbay, C., İsmet, B. O. Z., Tiryaki, G. Y., Candemir, S., ve Arpacı, B. B. (2012). Kahramanmaraş ve Gaziantep illerinde kırmızıbiberin üretim yapısı ve kurutma yöntemleri. Kahramanmaraş Sütçü Imam Üniversitesi Doğa Bilimleri dergisi, 15(2), 1-10.

Akça, A. ve Işık, D. (2016). Kayseri illi Şeker Pancarı (Beta vulgaris L.) ekiliş alanlarında bulunan yabancı otların tespiti. Bitki Koruma Bülteni, 56 (1), 115-124.

Anonim (2017). Dila biberi tescili. Doğu Akdeniz Geçit
Kuşağı Tarımsal

Araştırma

Enstitüsü, Kahramanmaraş.

Anonim (2018). Kahramanmaraş ili meteorolijk verileri. https://www.mgm.gov.tr/veridegerlendirme/il-veilceler-statistik.aspx?m=K.MARAS

Bewıck, T.A., L.K. Bınnıng, and M.N. Dana. (1988). Post attachment control of swamp dodder (Cuscuta gronovii) in cranberry (Vaccinium macrocarpon) and carrot (Daucus carota). Weed Technology, 2, 166169.

Costea, M., and Stefanović, S. (2010). Evolutionary history and taxonomy of the Cuscuta umbellata complex (Convolvulaceae), evidence of extensive hybridization from discordant nuclear and plastid phylogenies. Taxon, 59, 1783-1800.

Çakır, S. ve Üstüner, T. (2019). Küsküt'ün (Cuscuta campestris Yunck.) mercimek (Lens culinaris L.) bitkisel ve agronomik özelliklerine etkisinin araştırılması. Kahramanmaraş Sütçü İmam Üniversitesi, Fen Bilimleri Enstitüsü, Yüksek Lisans Tezi, Kahramanmaraş.

Davis, P.H. (1978). Flora of Turkey and east aegean Island. Edinburg University Press, 1-10.

Dawson J.H. (1984). Control of Cuscuta in alfalfa. In: Proceedings 3rd International Symposium Parasitic Weeds, 188-199.

Doymaz, i. and Pala, M. (2002). Hot-Air drying characteristics of red pepper. Journal of Food Engineering, 55, 331-335.

Duman, A.D., Zorlugenç, B. \& Evliya, B. (2002). Kahramanmaraş'ta Kırmızı biberin önemi ve sorunları. KSÜ Fen ve mühendislik dergisi, 5 (1), 111117.

Fang, R.C., Musselman, L. J. and Plitmann, U. (1995). Cuscuta in C.Y. Wu and P.H. Raven (eds.), Flora of China, Science Press, Beijing, and Missouri Botanical Garden Press, 16, 322-325.

FAO, (2017). Food and agriculture data. FAO web page, http://www.fao.org/faostat/en/\#data/QC___Erişim tarihi: 28.08.2019).

Güncan, A. (2001). Yabancı Otlar ve Mücadelesi. Konya, Türkiye. Selçuk Üniversitesi, Ziraat Fakültesi yayınları, 45-58.

Holm, L., Doll,J., Holm,E., Panch,J. and Herberger, J. (1997). World weeds: Natural histories and distribution, John Wiley \& Sons, New York. 1129.

Kadıŏlu, İ., Doğar, G. ve Ciğer, Ü. (2015). Şeker pancarı ekim alanlarında görülen küsküt (Cuscuta campestris Yunck.)'ün tanımı, zararı ve yaygınlık durumu. İstilacı Bitkiler Çalıştayı/Invasive Plants Work, 18 (3), 15-16.

Kaya, i., Nemli, Y. ve Demir, i. (2018). Türkiye'de tarım ve tarım dışı alanlarda görülen küsküt türlerinin (Cuscuta spp.) taksonomik özellikleri, dağılışları ve konukçuları. Turkish Journal of Weed Science, 21(1), 1-7.

Krsmanović, S. M., and Vrbničanin, S. (2015). Field dodderHow to control it?, Pestic. Phytomed, 30(3), 137-145.

Lanini, W.T. (2004). Economical methods of controlling dodder in tomatoes. Weed Science society, 56, 57-59.

Lanini, W.T. and Kogan, M. (2005). Biology and management of Cuscuta in crops. Ciencia $e$ Investigación Agraria, 32, 127-14 11.

Lawrence, H. M., (1965) Taxonomy of Vascular Plants. The 
Macmillan Company, Newyork, 823.

Mishra, J. S., Moorthy, B. T. S., Manish, B., and Yaduraju, N.T. (2007). Relative tolerance of rainy season crops to field dodder (Cuscuta campestris) and its management in Niger (Guizotiaa byssinica). Crop Protection, 26(4), 625-629.

Mishra, J.S. (2009). Biology and management of Cuscuta species. Indian Journal of Weed Science, 41(1 \& 2),111.

Mustapha, A. and Gworgwor, N. (2016). Effect of mechanical and chemical scarification on germination of Dodder (Cuscuta campestris Yunck.) seed. World Journal of Engineering and Technology, 03(03), 31-36.

Nadler-Hassar, T. and Rubin, B. (2003). Natural tolerance of Cuscuta campestris to herbicides inhibiting amino acid biosynthesis. Journal of Weed Research, 43(5), 341-347.

Nemli, Y. (1978). Çiçekli parazitlerden Cuscuta L. 'nin Anadolu türleri üzerindeki morfolojik ve sistematik araştırmalar, Ege üniversitesi, Ziraat Fakültesi Fitopatoloji ve Zirai botanik kürsüsü, Doçentlik Tezi, İzmir.

Nemli, Y. ve Öngen, N. (1982). Türkiye'nin Trakya bölgesi küsküt türleri (Cuscuta spp.) üzerinde taksonomik araştırmalar. Doğa Bilim Dergisi, 6(3), 147-154.

Nemli, Y. (1986). Anadolu'da kültür alanlarında bulunan küsküt türleri (Cuscuta spp. ); yayılışları ve konukçuları üzerinde araştırmalar, Ege üniversitesi, Ziraat Fakültesi dergisi, 23(3), 11-21.

Parker, C. and Riches, C.R. (1993). Cuscuta species, the dodders; and Cassytha filformis. In parasitic weeds of the worlds: Biology and control. CAB International, Wallingford, UK, 183-223.

Tamer, Ş.R. ve Nemli, Y. (2012). Farklı sıcaklıkların, bazı yeşil gübrelerin ve bitki eksudatlarının küskütün (Cuscuta campestris Yunck.; C. approximata Bab.) çimlenmesi üzerine etkileri. Ege Üniversitesi, Fen Bilimleri Enstitüsü, Yüksek Lisans Tezi. İzmir.

Tepe, I., Deveci, M. ve Keskin, B. (1997). Küsküt (Cuscuta approximata Bab.)'ün bazı yonca çeşitlerini parazitleme ve zarar seviyeleri üzerinde araştırmalar. Türkiye II. Herboloji Kongresi Bildirileri, 1-4 Eylül 1997, 355-360.

Topak, H., Erbil, N. ve Dığrak, M. (2008). Doğu Akdeniz ve Güneydoğu Anadolu bölgesinde yetiştirilen biberlerin antimikrobiyal aktivitesinin araştırılması. Fırat üniversitesi, Fen ve Mühendislik dergisi, 20 (2), 257264.

TUik, (2018). Türkiye bitkisel ürün istatistiği. https://biruni.tuik.gov.tr/medas/?kn=92\&locale=tr. (Erişim tarihi 28.08.2019)

Üstüner, T. ve Güncan, A. (2002). Niğde ve yöresi patates tarlalarında sorun olan yabancı otların yoğunluğu ve önemi ile topluluk oluşturmaları üzerine araştırmalar. Türkiye Herboloji Dergisi, 5(2), 30-42.

Üstüner, T. (2018). The effect of field dodder (Cuscuta campestris Yunck.) on the leaf and tuber yield of sugar beet (Beta vulgaris L.). Turkish journal of Agriculture and Forestry, 42, 348-353.

Üstüner, T. ve Öztürk, E. (2018). Şeker pancarı (Beta vulgaris L.) tarımında küskütün (Cuscuta campestris Yunc.) verim ve kalitye etkisi. Bitki Koruma Bülteni, 58 (1), 32-40.

Vrbničanin, S., Sarić-Krsmanović, M. and Božić, D. (2013). The effect of field dodder (Cuscuta campestris Yunck.) on morphological and fluorescence parameters of giant ragweed (Ambrosia trifida L.). Pesticides and Phytomedicine, 28(1), 57-62.

Yuncker, T.G. (1932). The genus Cuscuta. Memoirs of the Torrey Botanical Club, 18, 113-331.

ZharZharasov, S.U. (2009). Field dodder in the South east of Kazakhstan. Zashcita i Karantin Rastenii, 1, 30-32. 